\title{
IV. ULUSLARARASI TÜRK DÜNYASI EKONOMI FORUMU DÜZENLENDİ
}

Şahin YETIK ${ }^{1}$

Uluslararası Türk Dünyası Ekonomi Forumu dizisinin dördüncüsü 7-9 Mayıs 2015 tarihleri arasında Yabancı Diller ve Mesleki Kariyer Üniversitesi ve Hitit Üniversitesi işbirliğinde Çorum'da Hitit Üniversitesinin ev sahipliğinde gerçekleştirildi.

Foruma Türk dünyası başta olmak üzere birçok ülkeden 200'den fazla akademisyenin yanı sira Kazakistan Yabanc1 Diller ve Mesleki Kariyer Üniversitesi Rektörü Prof. Dr. Sabri Hizmetli, Kırgızistan Türkiye Manas Üniversitesi Rektörü Prof. Dr. Sabahattin Balcı, İslami İlimler Araştırma Vakfı Başkanı Prof. Dr. Ali Özek, Kazakistan eski Dinişleri Başkanı Abdüssettar Derviş Aliyev, Pamukkale Üniversitesi Rektörü Prof. Dr. Hüseyin Bağc1, Sinop Üniversitesi Rektörü Prof. Dr. Recep Bircan, sivil toplum kuruluşlarının temsilcileri, işadamları, sanayiciler ile ülkemizden ve Türk Cumhuriyetlerinden akademisyenler ve Çorum Valisi Ahmet Kara katıldı.

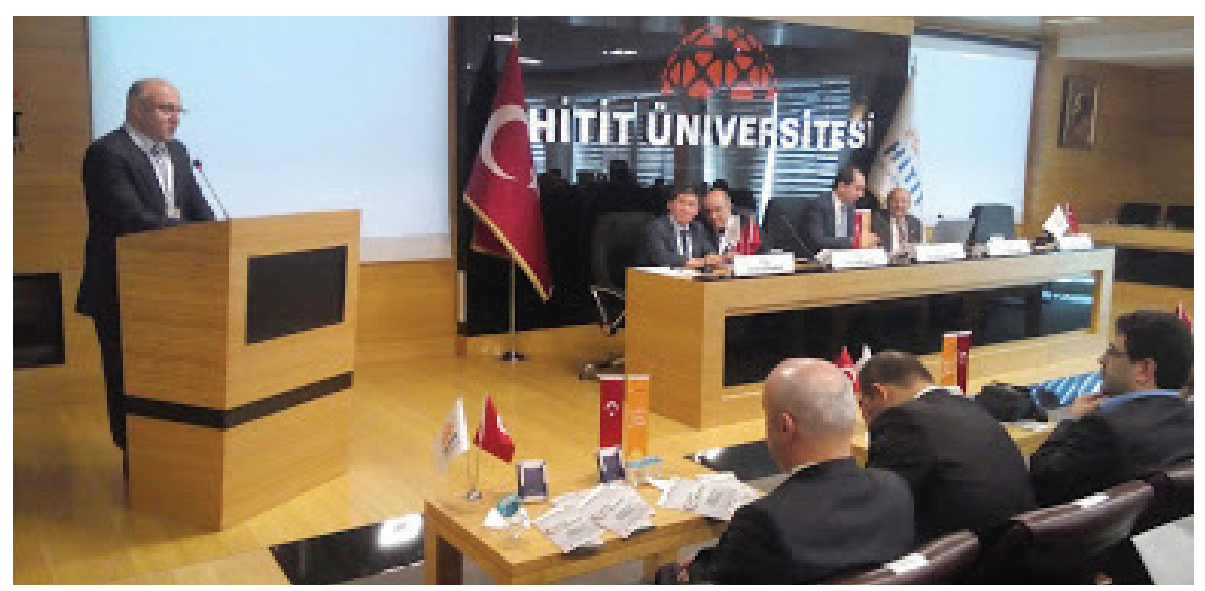

Üç gün boyunca devam eden Forumda toplam 39 oturum yapıld1. Forumda Türk Dünyası özelinde ekonomi, ticaret, kalkınma, kültür ve turizm konuları ele alınmakla beraber, pek çok akademisyen ve bilim adamı da kendi alanları ile ilgili sunum yapmıştır. Bu açıdan da Forum "ekonomi” üst başlı̆̆ında olsa

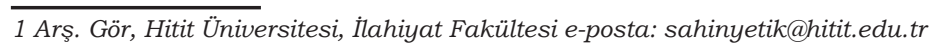


da genel itibariyle bir sosyal bilimler bilgi şöleni şeklinde gerçekleşmiştir.

Bilimsel veriler ışığında ekonomiden turizme kadar muhtelif pek çok konuda çözüm önerileri sunan ve yol haritaları çizen akademisyenlerin büyük bir çoğunluğunun Türk Dünyasının geleceği noktasında Türkiye'nin oynadığ rolün önemine vurgu yapmaları dikkat çekici olmuştur. Ekonomisi ile güçlenmeye ve büyümeye devam eden Türkiye'nin yalnız Türk Dünyası için değil küreselleşmenin sonucu olarak tüm dünya için büyük bir stratejik öneme sahip olduğu vurgulandı. Dolayısı ile Türk Dünyası ülkelerinin Türkiye ile olan ilişkilerini ekonomi, ticaret, kalkınma, turizm ve diğer pek çok öncelikli alanlarda geliştirmesi gerekliliğinin altı çizildi.

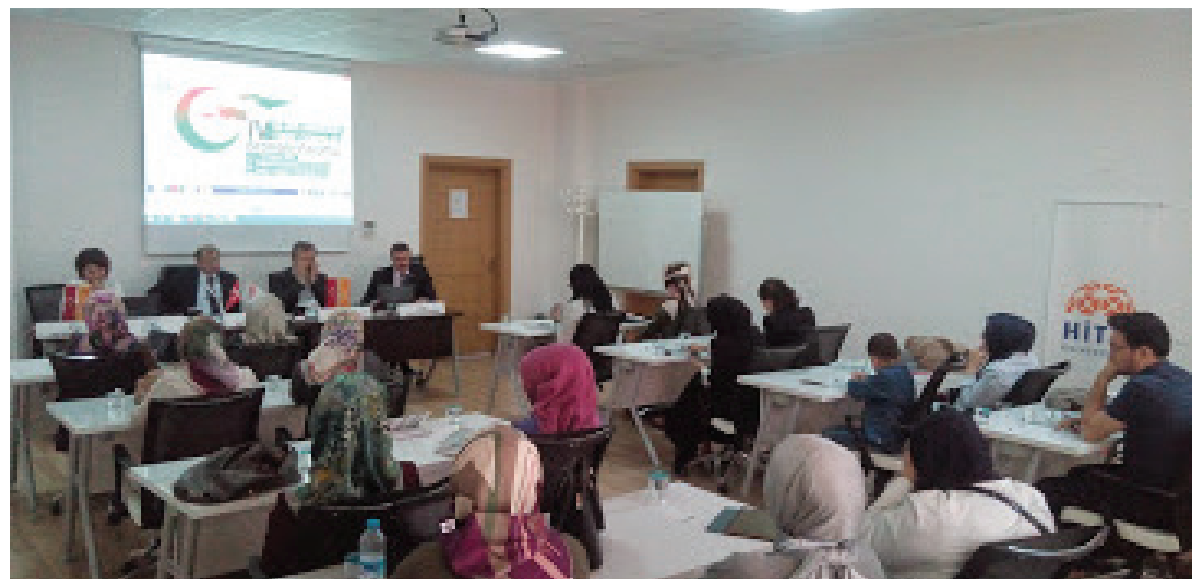

Genel olarak ifade edilecek olursa, Türk Dünyasının bilim, düşünce ve ekonomi alanında çalışan ve sorunların çözümü için çaba harcayan davetlilerin katılımları ile 7-9 Mayıs 2015 tarihlerinde gerçekleştirilen etkinliğin verimli bir şekilde tamamlandığı söylenebilir.

Etkinlikte en temel nokta olarak, Türk Dünyası aydınları, uzmanları ve akademisyenlerin buluşması sağlanmış, eğitim, ekonomi, kültür başta olmak üzere Türk Dünyasının çeşitli alanlarındaki problemleri ele alınmış ve çözüm yolları aranmıştır.

Forumun son günü Çorum Müzesi ve Çorum'un Boğazkale ilçesinde yer alan Hitit Medeniyetinin başkenti olan Hattuşa'ya gezi düzenlenmiş ve Hitit medeniyeti hakkında bilgilendirme turları yapılmıştır.

Etkinlikte sunulan tüm bildirilerin özetleri etkinlik internet sayfasında (tdef. hitit.edu.tr) pdf dosyası olarak yayınlanmış ve erişime açılmıştır. 


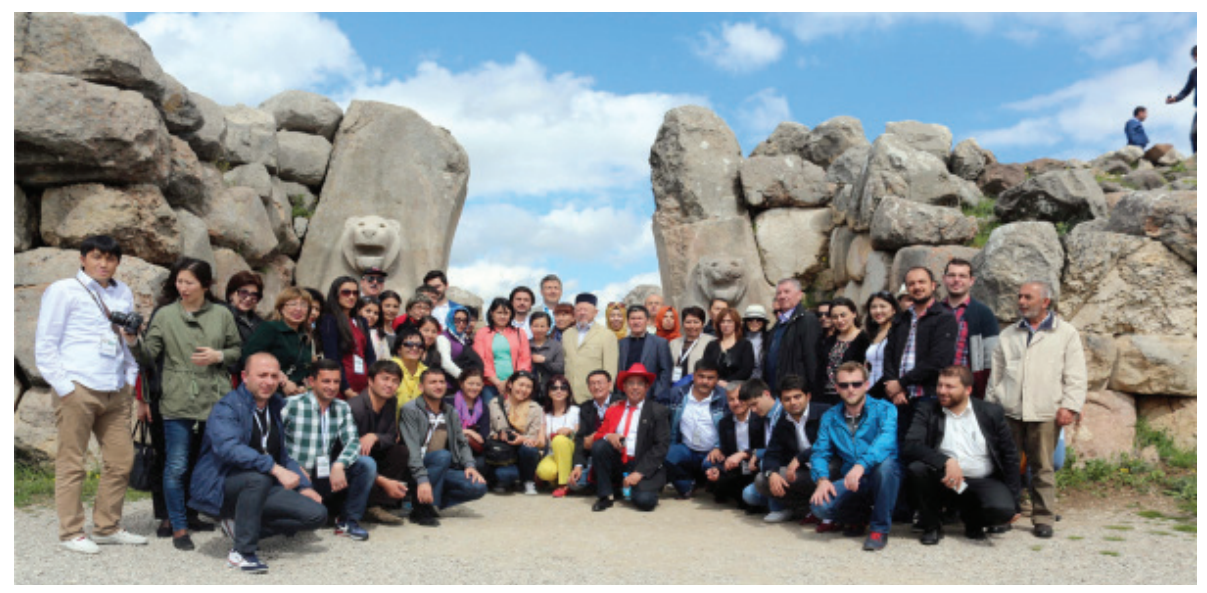

Ayrıca etkinlikte sunulan bildirilerden tam metinleri gözden geçirilip son şekli verildikten sonra yazıldıkları dile göre iki ayrı dergide basılacaktır. Türkçe ve İngilizce bildiriler, hakemlendikten sonra, başta TÜBİTAK-ULAKBİM olmak üzere 7 ayrı indeks tarafından taranan Hitit Üniversitesi Sosyal Bilimler Enstitüsü Dergisi’nin “Türk Dünyası Özel Sayısı”nda makale olarak yayınlanacaktır. 